\title{
Portable treatment technologies for urgent care
}

\author{
S Hignett, ${ }^{1}$ A Jones, ${ }^{1} \mathrm{~J} \mathrm{Benger}^{2}$
}

${ }^{1}$ Healthcare Ergonomics and Patient Safety Research Unit (HEPSU), Department of Human Sciences, Loughborough University, Loughborough, Leicestershire, UK ${ }^{2}$ Emergency Care, University of the West of England, Bristol, UK

\section{Correspondence to} Dr Sue Hignett, Healthcare Ergonomics and Patient Safety Research Unit (HEPSU), Department of Human Sciences, Loughborough University, Loughborough, Leics LE11 3TU, UK; S.M.Hignett@lboro.ac.uk

Accepted 28 July 2009 Published Online First

1 April 2010

\begin{abstract}
Background In recent years UK government policy has increased the provision of urgent care in the community. As part of this initiative the emergency ambulance service is gradually changing from an organisation designed to convey patients to hospital to a professional group capable of assessing urgency and delivering the appropriate treatment to the patient
\end{abstract}

Methods This paper explores the portable technology requirements needed to support the new professional roles and draws on examples from ambulance trusts (emergency care practitioner services), primary care (out-of-hours general practitioner services and minor injuries units), and acute trusts (emergency departments) to investigate the workplace layout and clinical activities, including the use of equipment and consumables. It describes the iterative process used to develop the design specification for portable technologies using a qualitative exploratory methodological framework with data collected at stakeholder workshops, responder bag audits, clinical treatment observations and design decision groups. Results The results are discussed as a three-level technology system for: personal kit; assessment packages (and storage for other clinical treatment packages), a clinical workspace. Future developments are predicted to improve diagnostic and decision-making services through both miniaturisation (eg, portable diagnostic imaging) and improved real-time support (communication systems).

Conclusion This study has provided empirical research for portable technology requirements in urgent care.

In May 2004 the Department of Health commissioned a strategic review of National Health Services (NHS) ambulance services in England, focussing on how the ambulance service could shift from providing resuscitation, trauma and acute care towards 'taking health care to the patient: transforming ambulance services in the community'.

Urgent care is defined as 'the range of responses that health and care services provide to people who require-or who perceive the need for-urgent advice, care, treatment or diagnosis. People using services and carers should expect 24/7 consistent and rigorous assessment of the urgency of their care need and an appropriate and prompt response to that need'. ${ }^{2}$ In 2007 the Royal College of General Practitioners commented that the organisation of urgent and unscheduled care services needed to improve to address the fragmentation of care services including duplication of provision, wasted resources and unnecessary handoffs between providers. They suggested the adoption of a 'whole systems approach' to ensure the integration of services and the creation of virtual urgent care centres for different providers to work together. ${ }^{3}$ Emergency and urgent care networks were therefore set up to coordinate and organise a diverse group of primary, secondary, out of hours (ambulance) and social services. ${ }^{4}$

Emergency and urgent care services are faced with the triple hurdle of delivering a service that is more responsive, more resource efficient, and that also uses the latest medical technologies. ${ }^{5}$ In 1999 the role of emergency care practitioner (ECP) was introduced. This role aimed to raise the clinical skills of paramedics, ensuring that patients receive the right care at the right time and in the right place. ${ }^{6}$ In 2004 Snooks et al $^{7}$ reviewed the early operational activities of ECP and found no significant difference in the rate of conveyance, but that a longer time was spent with patients, generating a more in-depth assessment with more comprehensive clinical records. By 2007 a different picture was emerging, with Mason et a ${ }^{8}$ finding that 'overall ECPs carried out fewer investigations, provided more treatments and were more likely to discharge patients home than usual providers', suggesting that the increased clinical skills were achieving the goal of delivering appropriate treatment to the patient without conveyance to hospital.

In order to achieve the vision of a modernised workforce that is able to provide a greater range of mobile urgent care, ambulance clinicians will need a wider range of competencies and underpinning knowledge while maintaining the vocational nature of their training. Many ambulance trusts are changing the profile of their workforce in line with the recommendations, including consideration of the interface between people, processes and technology using a sociotechnical framework. However, an initial review of the changed response/service model has identified potential risks including the poor state of fleet and equipment, and poor systems for integrating community responders. ${ }^{9}$

This project aimed to explore urgent care technology requirements (equipment and consumables) within a framework concept of a reconfigurable, rapidly exchangeable system of treatment technologies (portable and mobile). The objectives were to: understand and identify current and future care activities in emergency departments, minor injury units, ambulances and out-of-hours general practitioner services that could be delivered in the community and to develop design specifications for portable technologies.

\section{METHODS}

Qualitative data were collected using stakeholder workshops (2007, 2008), portable technology audits, treatment observations in emergency departments and walk-in centres and design decision groups (DDG; figure 1). All five datasets were 
Defining the scope: activities that could be delivered in the community Stakeholder workshops 2007

\begin{tabular}{|c|c|}
$\begin{array}{c}\text { Exploring current technologies } \\
E C P \text { bag audit }\end{array}$ & $\begin{array}{c}\text { Exploring clinical treatment practice } \\
\text { Observations }\end{array}$ \\
\hline
\end{tabular}

Review of data collection and analysis: member checking Stakeholder workshops 2008

Developing design specification Design Decision Groups

Figure 1 Project methodology.

analysed iteratively using NVivo, a qualitative data management program that supports coding, searching and theorising. ${ }^{10}$

One hundred and twenty-five staff and 88 patients participated over 18 months to give a range of perspectives about urgent care technologies from the acute, primary care and ambulance sectors (table 1). The research was granted NHS ethics committee approval (LNR1 REC reference 07/A2501/104) and written informed consent was obtained from all participants (patients and staff) before data collection commenced. Local research governance approval was obtained from each of the six participating NHS trusts.

The sampling followed a stepwise strategy that starts by selecting a wide range of participants to give variation on the dimensions of interest (mixed purposive sampling). ${ }^{11}$ The workshop participants represented the acute, community and ambulance sectors with a range of experience (12 months to 30 years). The second step followed up leads using stratified purposeful sampling to illustrate particular characteristics of a subgroup of interest (with the six complaints). The third stage (ECP bag audit) used homogenous sampling to minimise variation, focus and simplify the analysis. The final stage (analysis sampling) allowed testing of the ongoing analysis by using criterion sampling as a quality assurance approach for the DDG to recruit both fast response vehicles (FRV) and ECP. ${ }^{11} 12$

The scope of the project was defined at two professionally facilitated stakeholder workshops in 2007 (held in the East Midlands and South West regions of England). The participants were asked to list and categorise complaints that could be treated in the community currently and in the future by anticipating possible advances in medical science and technology. The outputs from the first workshop were refined in the second workshop to map core pathways and generate equipment lists. ${ }^{13}$ A set of six presenting complaints was selected for further study: breathing difficulties (physical minor); chest pain (physical uncertain); lacerations (physical minor); falls (physical uncertain/social); neck pain (physical minor); head injury (physical minor). ${ }^{14}$

The use of current technologies was explored by revisiting, updating and extending a previous audit of portable equipment

Table 1 Number of participants at each stage

\begin{tabular}{lcccc}
\hline & Acute & Primary care & Ambulance & Total \\
\hline 1 Stakeholder workshops 2007 & 5 & 9 & 8 & 22 \\
2 ECP bag audit & & & 13 & 13 \\
3 Observations & $53(\mathrm{~S})$ & $9(\mathrm{~S})$ & & $62(\mathrm{~S})$ \\
& $64(\mathrm{P})$ & $24(\mathrm{P})$ & & $88(\mathrm{P})$ \\
4 Stakeholder workshops 2008 & & & 15 & 15 \\
5 DDG & & & 13 & 13 \\
Total & $58(\mathrm{~S})$ & $18(\mathrm{~S})$ & 49 & $125(\mathrm{~S})$ \\
& $64(\mathrm{P})$ & $24(\mathrm{P})$ & & $88(\mathrm{P})$ \\
\hline
\end{tabular}

DDG, design decision group; ECP, emergency care practitioner; $P$, patients; $S$, staff. and consumables for ECP.15 16 Data were collected using interviews and a checklist and then grouped by complaint for comparison with the equipment lists from the 2007 stakeholder workshops.

Clinical treatment practices for urgent complaints were explored through 84 observations of patient treatment at two emergency departments and one walk-in centre for the six complaints. Data were recorded for the equipment and consumables used, staff movements and clinical procedures. ${ }^{14}{ }^{17}$ Interviews were carried out with staff to gain a better understanding of the treatment process for the hierarchical task analysis. ${ }^{18}$ Each hierarchical task analysis was coded for equipment used, treatment space requirements and procedural issues. Data were collected until theoretical saturation was achieved and no additional information was being generated from the observations.

In 2008 a second workshop was held with fleet (4), clinical (5), service (4) and health and safety managers (2) from five ambulance trusts to present the findings of the 2007 workshops, audits and observations. Data were collected as a series of semistructured questions in individual workbooks; these included challenges to clinical practice (rationalisation of equipment and consumables) and future scoping for the next 20 years. Key themes for future changes in clinical practice focused on diagnosis, with developments predicted in portability and decision-making support (communication).

Finally, two DDG were held to challenge current practice and support innovative redesign through round robins, word maps, mock-ups and prototypes. ${ }^{19}$ Thirteen emergency care practitioners, FRV and community paramedics were given an opportunity to prepare bags for specific care pathways (using the scenarios in table 2) and carry out drawing exercises to create portable treatment packages with improved functionality and usability. The different technologies for ECP and FRV were explicitly explored as many of the ECP reported that they worked in both roles (table 2). For the second session, working prototypes (two and three-dimensional) were used as the focus for the discussion and modification of the design requirements.

\section{RESULTS}

The 2007 workshops produced a list of equipment and consumables in treatment groups (table 3 ). These groups were further populated with the data from the audits and the clinical observations (equipment and consumables, table 3).

Table 2 Care pathways for DDG

\begin{tabular}{|c|c|}
\hline ECP/FRV & Scenario for care pathway \\
\hline $\begin{array}{l}\mathrm{ECP}^{1} \\
\text { Head injury/ } \\
\text { laceration }\end{array}$ & $\begin{array}{l}\text { 74-year-old woman phones in with small }(2-3 \mathrm{~cm}) \text { laceration to } \\
\text { scalp and feeling generally unwell. She hit her head on a shelf while } \\
\text { standing up. She is fully conscious and alert, with known type } 2 \\
\text { diabetes and no known history of hypotension. She lives with } \\
\text { husband who is well and able to care for her. }\end{array}$ \\
\hline $\begin{array}{l}\mathrm{ECP}^{2} \\
\text { Fall/laceration }\end{array}$ & $\begin{array}{l}\text { Called to see } 75 \text {-year-old woman who has been experiencing } \\
\text { abdominal pains for several days and has stumbled today, resulting } \\
\text { in a minor leg laceration. She has not been seen by anyone for } \\
\text { a few days and is found in her living room. }\end{array}$ \\
\hline $\mathrm{FRV}^{1}$ & $\begin{array}{l}\text { 68-year-old man is unwell. On further investigation he is found to be } \\
\text { experiencing chest pain. He is found in a supermarket car park, } \\
\text { sitting in the front seat of a car with limited space around. The } \\
\text { patient is mobile and it is a hot, sunny day. }\end{array}$ \\
\hline $\mathrm{FRV}^{2}$ & $\begin{array}{l}\text { 22-year-old man complaining of severe neck pain after rear end } \\
\text { shunt road traffic accident as an unrestrained front seat passenger. } \\
\text { Car was travelling at } 45 \mathrm{mph} \text { (in } 30 \mathrm{mph} \text { zone). Patient has pins and } \\
\text { needles radiating down both arms (bulls eye on windscreen). } \\
\text { Normally fit and well. No visible haemorrhage, no further injuries } \\
\text { reported. Driver is uninjured and currently talking to police. Patient } \\
\text { found still in passenger seat. }\end{array}$ \\
\hline
\end{tabular}

DDG, design decision group; ECP, emergency care practitioner; FRV, fast response vehicle. 


\section{Original article}

Table 3 Treatment groups from 2007 workshops with equipment and consumables from clinical observations

\section{Treatment groups}

Minor wounds

Ear, nose and throat

Respiratory

Blood monitoring

Eyes

Basic life support

Communications:

Urinary

General

Drugs

\section{Equipment/consumables}

Dressing pack, irrigation fluid, forceps, scissors, tissue glue, steristrips, suture kit (sutures and instruments)

Tongue depressors, thermometer (tympanic), suction, auroscope

Oxygen masks (including tracheostomy), stethoscope, pulse oximetre, nebuliser, nasal and oral airways, peak flow metre, suction kit

Specimen bottles, phlebotomy kit, blood pressure cuff, cannula (various), giving sets, blood glucose testing strips

Irrigation fluid, eye pads

Defibrillator, oxygen, face mask, electrocardiogram (ECG) capability (computerised transmissible)

Mobile telephone, telemedicine capability, on-line decision support software

Urinalysis kit, sample bottles, catheter equipment, incontinence pads

Gloves (sterile/non-sterile), neck collar, bandages, gauzes, dressings, waste bins (sharps, clinical, domestic), sphygmomanometer, skin preparation wipes, apron, hand wash facilities, tissues, syringes, needles, lubricant, magnifying glass, razor, tweezers, scissors, referral letter/x-ray/prescription (prescribing guidelines), patella hammer, ring cutter, safety glasses, helmet

Glyceryl trinitrate (GTN) spray, aspirin, intravenous fluids, paracetamol, anti-inflammatories, antibiotics, local anaesthetics

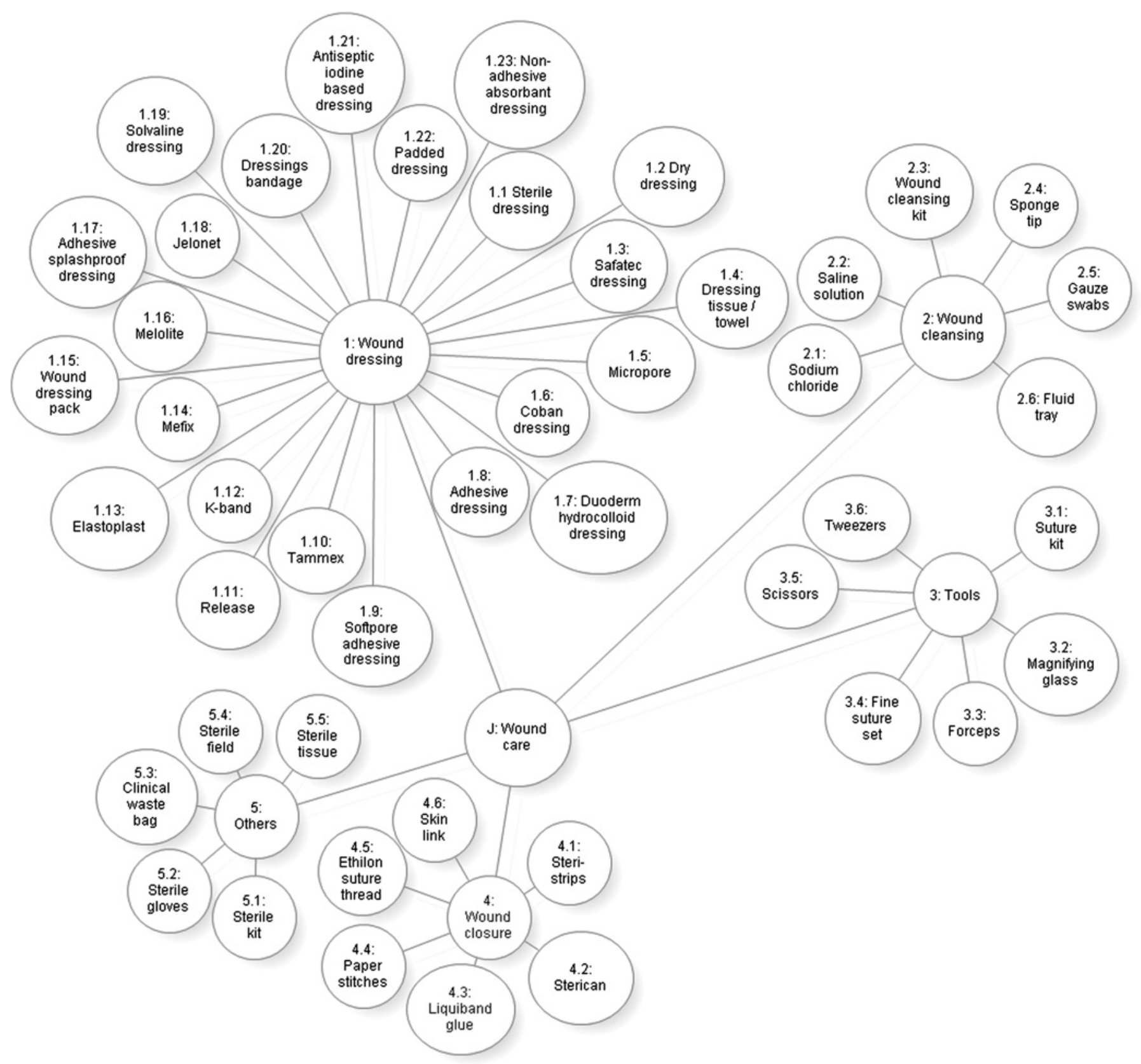

Figure 2 Example of triangulation of four datasets for wound care. 
Table 4 Personal kit and assessment/treatment packages for urgent care

\begin{tabular}{ll}
\hline 1. Personal kit & 2. Assessment pack \\
\hline Gloves, pen torch, phone, stethoscope, & BP cuff, thermometre, BM kit, urinalysis, peak \\
scissors, drugs guide (eg, British National & flow metre, opthalomo/otoscope, tongue \\
$\begin{array}{ll}\text { Formulary), coat, helmet, stab vest, } & \text { depressor, tendon hammer, KY jelly, apron, patient } \\
\text { fleece, radio, tourniquet } & \text { record form, clinical disposal bag, sharps box }\end{array}$ \\
\hline
\end{tabular}

BM, blood monitoring; BP, blood pressure; IV, intravenous.

The analysis of the 2008 workshops resulted in thematic codes including individual preferences, dimensions of the storage (bag/s), infection transmission risks, standardisation of the contents, layout, disposable packs and containers and clinical 'job' organisation (eg, breathing difficulties treatment pack).

The triangulated data from the four datasets (stakeholder workshops in 2007 and 2008, ECP bag audit and observations) were reviewed by the second researcher before being taken to the DDG. This resulted in eight primary themes: wound care (figure 2); drugs, gases and vaccines; diagnostic equipment; office stationery; hygiene/sanitation; additional technologies (eg, razor); immobilisation (eg, splint/sling) and phlebotomy equipment/consumables.

The data from the first DDG (round robin, word map, care pathways) resulted in six categories of equipment and consumables: hygiene/sanitation; drugs; intravenous access; wound care; patient assessment; others. These data were taken forward to the second DDG in the two and three-dimensional mock-ups and prototypes. From these iterations it emerged that the supporting portable technologies for urgent care should consist of a three-level technology system for: personal kit; assessment packages (and storage for other clinical treatment packages) as shown in table 4; and a clinical workspace (equivalent to an emergency department treatment trolley).

\section{DISCUSSION}

We have successfully explored the portable technology requirements needed to support new professional roles that are designed to deliver urgent care in the community, defining a three-level technology system for personal kit, assessment packages and a clinical workspace.

The triangulated data and outputs from the DDG were reviewed independently by two researchers (AJ and $\mathrm{SH})$ to crosscheck the treatment groupings and the technology requirements. The personal and assessment packs were found to match closely the recommendations for doctors' bags from Hiramanek et al. ${ }^{20}$ Overall, it emerged that a single use, modular pack concept was the preferred approach to provide efficient clinical treatment and also to improve infection control, restocking and storage. Poland et $a l^{21}$ questioned whether interventions (eg, standardised equipment/consumables) would necessarily bring benefits. They suggested that professional work is 'constructed as requiring the identification of best practices through careful and rigorous empirical evaluative research and "applying" these as faithfully as possible'; however, it is important to retain clinical autonomy in diagnosis and treatment so a degree of flexibility will be necessary to support individual variation (in both the clinical practitioner and patient).

A modular design, including 'grab bags' may provide the optimal solution; this design approach will be explored further. This concept has also been proposed by Nakar et $\mathrm{al}^{22}$ as a system for doctors' bags to facilitate efficient working using a set of prepared bags (in addition to an assessment kit similar to table 4) that includes both clinical and administrative supplies.

The qualitative methodology in this study allowed the exploration of complex working activities from a range of perspectives, using both visual and written data. The iterative data collection and analysis allowed the development of a robust audit trail that included specific member checking (stakeholder workshops 2008) for the detailed analysis as well as a two-stage final DDG to challenge possible limitations of the recommendations for urgent (ECP) and emergency (FRV) clinical activities.

The limitations of the study apply to both the methodology and generalisability. As with any qualitative study, there are limitations about the quantity of data due to the small number of participants. To address the reliability of the data collection and analysis we have given details about process (audit trail) and coding for all of the datasets. The analytical induction (final criterion sampling strategy) strengthened the validity of the data interpretation by enabling us to review the findings and recommendations for the modular pack concept.

\section{CONCLUSION}

The data produced from this research provide a robust foundation for the development of a portable technology system for urgent care in the community. They have produced design specifications based on clinical activities, with data drawn from acute, primary care and ambulance sectors. The final design specification is now ready to be developed and validated in clinical practice. The next stage will be carried out in conjunction with the National Ambulance Fleet Strategy Group.

\begin{abstract}
Acknowledgements The authors would like to thank the EPSRC for funding the Smart Pods project and their partners at the Royal College of Art, Bath and Plymouth Universities. They would particularly like to acknowledge the contribution of the six participating NHS trusts: University Hospitals Bristol NHS Foundation Trust, University Hospitals Leicester Foundation NHS Trust, BrisDoc, Leicester County and Rutland Primary Care NHS Trust, Great Western Ambulance Service NHS Trust and East Midlands Ambulance Service NHS Trust.
\end{abstract}

Funding Engineering and Physical Science Research council grant ref no $\mathrm{EP} / \mathrm{F002920/1}$

\section{Competing interests None.}

\section{Patient consent Obtained.}

Ethics approval The research was granted NHS ethics committee approval (LNR1 REC reference 07/A2501/104). Local research governance approval was obtained from each of the six participating NHS trusts.

Contributors SH (guarantor) and IB are the principal and co-investigators. They developed the research idea and protocol, negotiated access and wrote this paper. AJ collected and analysed the data and prepared a preliminary report with assistance from SH and IB.

Provenance and peer review Not commissioned; externally peer reviewed.

\section{REFERENCES}

1. Department of Health. Taking healthcare to the patient. Transforming NHS Ambulance Services. 2000. http://www.dh.gov.uk/assetRoot/04/11/42/70/ 04114270.pdf (accessed 9 Feb 2009).

2. Department of Health. Urgent care: direction of travel. Consultation document London: Department of Health 2000.

3. Lakhani M, Fernandes A, Archard G. Urgent care: a position statement from the Royal College of General Practitioners. London: Royal College of General Practitioners 2007.

4. Turner J, Nicholl J, O'Caithain A. A preliminary study of Emergency and Urgent Care Networks. 2008. http://www.dh.gov.uk/en/Consultations/Responsestoconsultations/ DH_080364 (accessed 9 Feb 2009) 
5. Phillips W, Caldwell N. Supplying innovative healthcare technologies into the UK healthcare sector: a literature review. Internal document. UK: Centre for Research in Strategic Purchasing and Supply, University of Bath School of Management, 2007.

6. Department of Health. The emergency care practitioner report - right skill, right time, right place. 2004. http://www.dh.gov.uk/en/Publicationsandstatistics/ Publications/PublicationsPolicyAndGuidance/DH 4093086 (accessed 9 Feb 2009).

7. Snooks H, Kearsley N, Dale J, et al. Towards primary care for non-serious callers to the emergency ambulance service: results of 'treat and refer' protocols for ambulance crews. Qual Saf Health Care 2004:13:435-43.

8. Mason S, O'Keeffe C, Coleman P, et al. Effectiveness of emergency care practitioners working within existing emergency service models of care. Emerg Med J 2007:24:239-43.

9. DH Ambulance Policy. Changing times: sustaining long-term performance against 'call connect' for NHS Ambulance Services. London: Department of Health, 2008.

10. Bazeley P, Richards L. The NVivo ${ }^{\circledR}$ qualitative project book. London: Sage Publications, 2000.

11. Patton MQ. How to use qualitative methods in evaluation. Newbury Park, CA: Sage Publications Inc, 1990.

12. Hignett S. Qualitative methodology for ergonomics. Chapter 5. In: Wilson JR, Corlett EN, eds. Evaluation of human work. A practical ergonomics methodology. 3rd ed. Boca Raton, FL: CRC Press, 2005:113-28.

13. Jones A, Hignett $S$, Benger J. Identifying current and future care activities in ambulances, emergency departments and primary care. Emerg Med J 2008;25(Suppl):A3.
14. Jones A, Hignett S, Benger J. A comparison of urgent tasks and workspace design in pre-hospital care. In: Hignett S, Norris B, Catchpole K, et al, eds. From safe design to safe practice. Proceedings of the Improving Patient Safety Conference. Cambridge, 16-18 July 2008, 121-5. Loughborough: The Ergonomics Society.

15. Redden D. An evaluation of fast response vehicle paramedic bag systems. MSC dissertation. Loughborough University: Department of Human Sciences, 2002.

16. Reynolds R. Standardisation of emergency care practitioners equipment and consumables. BSc dissertation. Loughborough University: Department of Human Sciences, 2008.

17. Ferreira J, Hignett $\mathrm{S}$. Reviewing ambulance design for clinical efficiency and paramedic safety. Appl Ergon 2005;36:97-105.

18. Annett J. Hierarchical task analysis (HTA). In: Stanton N, Hedge A, Brookwillis K et al, eds. Handbook of human factors and ergonomics methods. London: CRC Press, 2005:33.1-33.7.

19. Wilson JW, Haines H, Morris W. Participatory ergonomics. In: Wilson JW, Corlett EN, eds. Evaluation of human work. 3rd ed. London: Taylor and Francis, 2005:933-62.

20. Hiramanek N, O'Shea $\mathrm{C}$, Lee $\mathrm{C}$, et al. What's in the doctor's bag? Aust Fam Physician 2004;33:714-20.

21. Poland B, Lehoux $P$, Holmes $D$, et al. How place matters: unpacking technology and power in health and social care. Health Soc Care Community 2005;13:170-80.

22. Nakar S, Vinker S, Weingarten M. What family physicians need in their doctor's bag Fam Pract 1995:12:430-2.

\section{Images in emergency medicine}

\section{Importance of magnifying CT images to detect minute free air in patients with blunt bowel injury}

A 17-year-old man was hit by a car while riding his bicycle. On arrival at hospital his physiological findings showed abdominal tenderness and weak bowel sounds. A plain abdominal CT scan was performed on arrival, 90 min after the accident. By changing the window and the level of the CT image and magnifying the CT image, minute free air (Figure 1, triangle) could be seen with thickening of the small intestine, suggesting a perforation of the small intestine, An emergency laparotomy indicated that there was a perforation of the jejunum. The patient's postoperative course was uneventful.

This case report adds to the list of interpretative techniques that can be used to make the most of CT images and to best detect free air soon after trauma.

\section{Youichi Yanagawa, Satomi Fukazawa, Tomonori Imamura}

Department of Traumatology and Critical Care Medicine, National Defense Medical College, Japan

Correspondence to Youichi Yanagawa, Department of Traumatology and Critical Care Medicine, National Defense Medical College, 3-2 Namiki Tokorozawa, Saitama 359-8513, Japan; yanagawa@ndmc.ac.jp

Competing interests None.

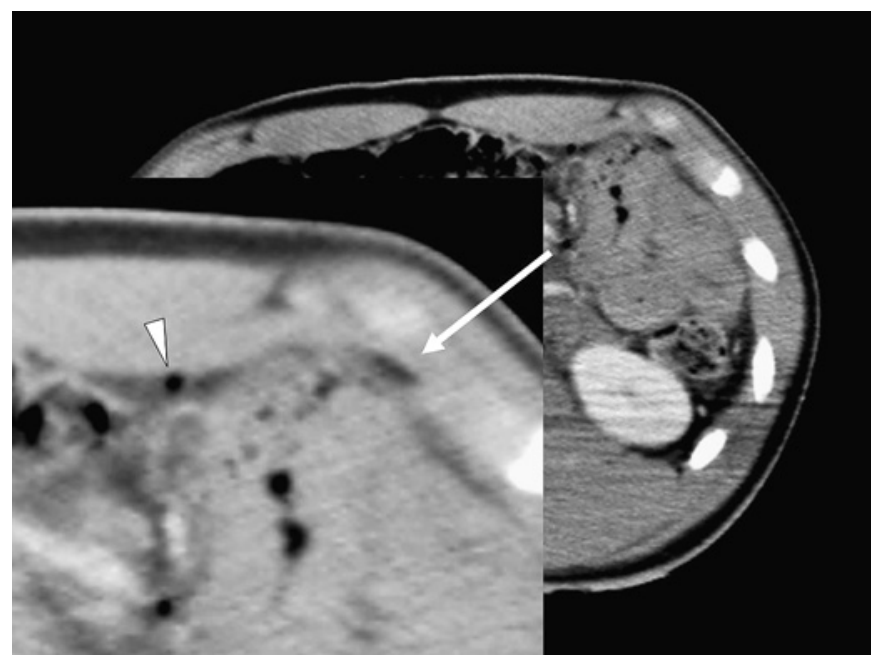

Figure 1 Abdominal CT scan on arrival. Free air (triangle) with thickening of the small intestine can be seen in the magnified image (inset; window 400, level 10).

\section{Patient consent Obtained}

Provenance and peer review Not commissioned; not externally peer reviewed.

Accepted 6 April 2010

Published Online First 10 November 2010

Emerg Med J 2011;28:196. doi:10.1136/emj.2010.095521 


\title{
Portable treatment technologies for urgent
} care

\author{
S Hignett, $\mathrm{A}$ Jones and J Benger
}

Emerg Med J 2011 28: 192-196 originally published online April 1, 2010 doi: 10.1136/emj.2009.075010

Updated information and services can be found at:

http://emj.bmj.com/content/28/3/192.full.html

\section{These include:}

References This article cites 7 articles, 3 of which can be accessed free at: http://emj.bmj.com/content/28/3/192.full.html\#ref-list-1

Email alerting Receive free email alerts when new articles cite this article. Sign up in service the box at the top right corner of the online article.

Notes

To request permissions go to:

http://group.bmj.com/group/rights-licensing/permissions

To order reprints go to:

http://journals.bmj.com/cgi/reprintform

To subscribe to BMJ go to:

http://group.bmj.com/subscribe/ 